\title{
Pub Philosophy
}

\section{Shaw}

Published online: 24 January 2019

(C) Journal of Bioethical Inquiry Pty Ltd. 2019

Keywords Pubs · Philosophy Ethics $\cdot$ Public health Risk $\cdot$ Alcohol

\section{Introduction}

Last night I had planned to go into town with my friends for a drink. Yesterday morning one of them warned that he had a cold so might not make it; I replied that I had a cold and had been up half the night with my son but I was still going. Later that afternoon another friend apologized, saying he had to work late, while also helpfully sharing a link to an article about how to avoid being the annoying one in a conversation. So my remaining friend and I decided not to go into town after all and went to the local pub. This meant it was a healthier evening because I had to walk three miles total there and back instead of just a mile going to and from the train station and also because we bought one round each for two people instead of four, meaning that we had two drinks each instead of four. We had a good chat and even discussed some philosophy before heading home. Today at work I don't even have a hangover.

\section{Shaw}

Institute for Biomedical Ethics, University of Basel,

Bernoulistrassse 28, 4056 Basel, Switzerland

D. Shaw $(\bowtie)$

Department of Health, Ethics and Society, Care and Public Health Research Institute, Maastricht University, Maastricht, the

Netherlands

e-mail: David.shaw@unibas.ch
The moral of this story is that going to the pub raises many interesting philosophical issues, some of which pose ethical dilemmas; in this particular anecdote, we have the delicate etiquette of withdrawing from an arrangement, the health issues concerning alcohol consumption and exercise, the justice issues raised by taking turns to buy drinks, and appropriate conversational topics. This paper explains and explores all these issues and more, covering aspects of social philosophy, medical ethics, distributive justice, risk, and decision theory.

\section{Planning the Pint: The Pre-Pub Conversation}

One does not simply walk into a pub with one's friends: planning is required. Agreeing on a date, choosing a venue, and choosing a time might seem like simple endeavours, but can constitute an ethical minefield. First, it has to be decided who is to be invited. In a small circle of friends this is easy enough, but in a larger group it can become awkward. Often one person has two groups of friends and wants to invite them all to the pub, except that members of one group don't really get on with members of the other (hence, partially, their classification into groups). More subtly, in many cases some friends are just closer than others, and though there is no wish to exclude any particular friend, it is tacitly understood that if that person is invited the opportunity for forthright discussion on particular topics will be curtailed - or simply that that person will dominate the conversation with monologues when the intention is to at least attempt some 
approximation of a dialogue. These concerns can lead to stepwise planning, where a small number of friends settle on a date, and then one of them timidly asks whether X should be invited along as well. Even if the others subscribe to the description of $\mathrm{X}$ as a monologuing sociopath, there will (at least in Britain) be some reluctance to actually say so, and so X might end up being invited, despite the hidden hope that $\mathrm{X}$ won't be able to come on that date anyway. If/when $\mathrm{X}$ is finally invited, there is also a risk/hope that he or she will say no because he or she was not involved in planning the date. (It should also be noted that many people would never admit that anything described in this paragraph actually occurs, as it's all a bit awkward. It should also be noted that my wife Justine insists that women don't get hung up on all this nonsense.)

As well as affecting the number of drinks consumed in an evening (see later in paper), the quality of conversation and hence of the evening itself can also be affected by the number of people present. If there are three or four or five or even six friends, all can easily talk to each other at one table, but if there are seven or more then sub-conversations will start and mini-resentments can develop at not being able to talk to who you actually want to talk to- particularly if people from two groups (as described above) are attending. While most friends will want to be inclusive, the fact that smaller groups often lead to better evenings (and smaller hangovers) generates a conflict of interest that may cause bias against expanding the circle of those invited.

Once it has been decided who is coming, the venue must be settled upon. (Of course, sometimes someone might be excluded because everyone else likes a particular venue but one person doesn't.) This can be challenging due to preferences regarding beer, music, relative distance, and even decor. Different friends might even have different definitions of a pub or disagree on what makes a perfect pub. What is a pub anyway? The word is an abbreviated form of "public house" but that is not a very informative term for anyone unfamiliar with such establishments. Essentially a pub is a place that serves alcoholic drinks and has a place to sit, but that rather spartan definition covers a vast variety of pubs. My own preference is for pubs with music, no screens, and a wide choice of beers. My friend Gordon doesn't mind music, likes screens in case the football is on, and positively dislikes a wide choice of beers because that often means he has to hunt hard for a standard lager, which is his standard drink. To take another example, some people don't regard gastropubs as pubs because they're more like hipster restaurants and cost a fortune. The choice of venue might also be affected by the chosen date and its relation to any entertainment taking place in the pub and vice versa. For example, although it is fairly basic in terms of beers I don't mind having the odd pint at my "local" as it's the nearest pub to my house (by definition). However, I don't like it on quiz nights, because it's impossible to talk to my friends because of their insistence on listening closely to all the quiz questions. Conversely, they all like quiz nights because on those occasions they don't have to listen to me banging on about philosophy.

My friends Paul and David prefer city-centre pubs because the former lives in the city centre and the latter lives in the countryside and getting to town is easier than coming out to the suburb where both Gordon and I live. This means that Gordon and I end up going into town rather more often than we would choose, but we can hardly insist that our friends come to us when the choice of pubs and potential for agreeable disagreement about which one to go to is so much greater in town. Assuming that we agree on the pub, one final issue that has to be settled in fine weather is whether to sit inside or outside. Generally, twenty years ago we would always have sat outside, but outdoors sitting areas are now full of resentful smokers who can no longer give themselves lung cancer inside the pub. That's good when the weather is bad but not very pleasant when the weather is pleasant, particularly for families who want to sit outside. Of course, there will often be someone (often Gordon) who says it's too cold to sit outside even if it's twenty degrees and sunny. (In the winter, it seems likely that smokers' health must suffer as they are forced to smoke outside in sub-zero temperatures. In some groups of friends, non-smokers can also be found outside because the locus of conversation follows the smokers.)

Despite these aforementioned complications, organizing nights out with friends has been made much easier with social media and group messaging, enabling the night to be planned without actually talking to anyone. However, this method of communication has the drawback that it requires people to actually respond. Often one or more people in such a conversation will fail to do so, letting the others settle on a date that then turns out not to suit the silent partner. That person then belatedly says that that date doesn't suit, causing (hopefully transient) resentment. Similarly, sometimes a venue is agreed upon, but on the day of the drinks one friend (probably the same one) asks "where are we going tonight then?" only to be told to scroll back up for the 
answer. On the other hand, sometimes the conversation involved in planning the night out is actually more amusing than the night out itself.

The last part of the pre-pub conversation concerns when to meet and whether to meet at some transit point prior to the pub. Normally it would make sense just to wait until we're at the pub, but some people don't like sitting by themselves waiting in a warm pub and would rather stand in the cold outside a station.

Once you're all actually at the pub, conversations can obviously cover a vast array of topics, and providing a philosophical analysis of all of them is unfortunately outwith the scope of this article. As well as the mainstays of work, family, sport, TV, movies, and partners, there are some subjects that actually ought to be discussed when friends are together. Chief among these is organ donation. While it might seem inappropriate to discuss donating one's organs while doing one's best to pickle them in alcohol, it is important to share one's wishes regarding organ donation with one's friends and important to get them to consider donating too. If the worst comes to the worst, one of you might need a liver transplant before too long; for some people the point of the pub is not conversation but drinking.

\section{Pubs and Public Health}

Before buying the first drink, a brief diversion: it would be irresponsible for an article about the philosophy of pub-going not to have a health warning attached to it. So, as implied by the preceding paragraphs: drinking alcohol can harm your health. However, although drinking alcohol can clearly be harmful, it's nowhere near as risky as some doctors and scare stories in newspapers claim. In fact, many alcohol health warnings should have logic warnings attached. For example, when the "safe" weekly alcohol limit for men was lowered to fourteen units in line with the female limit (UK Department of Health 2016) the Chief Medical Officer argued as follows:

If you take 1,000 women, 110 will get breast cancer without drinking. Drink up to these guidelines and an extra 20 women will get cancer because of that drinking. Double the guideline limit and an extra 50 women per 1,000 will get cancer ... That's not scaremongering, that's fact and it's hard science (Weaver 2016, II5)
This might make for sobering reading for some people (literally) but a more helpful way of communicating the same facts would be "you can drink twice what we recommend and there's only a 5\% chance that you'll get cancer as a result - and in any case there's a 10\% chance you'll get cancer even if you don't drink" (Shaw 2016, I[3).

In a more recent case, a large study in the Lancet found that "there is no safe level of drinking". As David Spiegelhalter pointed out in an excellent critique (Spiegelhalter 2018), this paper did not even provide any absolute risk statistics - but the press release linked to the article surprisingly did. It summarized the main findings as follows: "comparing no drinks with one drink a day the risk of developing one of the 23 alcohol-related health problems was $0.5 \%$ higher-meaning 914 in $100,00015-95$ year olds would develop a condition in one year if they did not drink, but 918 people in 100,000 who drank one alcoholic drink a day would develop an alcohol-related health problem in a year" (The Lancet 2018, II6 under "Risks Associated With Alcohol”). Or, to put it differently, for 99,996 out of every 100,000 people drinking one drink a day, it does them no harm whatsoever and presumably they would enjoy those drinks. As Spiegelhalter states the risk, if 25,000 people each drank 16 bottles of gin a year, you would only get ONE additional health problem from all that drinking. Does that mean that there is no safe level of drinking? (Discuss over a pint.) The lesson from both these examples is that it's risky to talk about the risks of alcohol without giving a baseline statistic for the underlying rate of mortality, even if it does make sense to keep track of how many units you've drunk on a night out (see next section).

As well as requiring some decision theory and risk assessment, going to the pub also involves some skill in mathematics or at least basic arithmetic. If health guidelines are provided in terms of units, it will be helpful to know what a unit is and how to calculate the number of units in a given alcoholic drink. Most people don't know either of these things, so here is a quick guide. A unit is $10 \mathrm{ml}$ of pure alcohol. Luckily most pubs don't serve that as a drink, but it equates to $25 \mathrm{ml}$ of 40 per cent whisky (a single measure, unless it's one of those rare pubs that serves $35 \mathrm{ml}$ measures). Similarly, a pint of 4 per cent beer is just over two units, and a "large" (though small compared to the ones people have at home) glass of wine $(250 \mathrm{ml})$ is likely to be over three units assuming that the wine is 12 per cent. Getting your head around these calculations is hard enough when you are sober, so it's hardly surprising that people start to lose track when they 
try to count units while actually consuming them (as Morrissey once sang in a helpful description of British pub culture, "and so I drank one, it became four, and when I fell on the floor I drank more"). Binge drinking is commonly regarded as having very many drinks in one session, but technically a binge is anything over six units for men or women (UK National Health Service 2016). (Interestingly, the definition of binging provided on Drinkaware's website states that it is eight units for men and six for women, the older definition [Drinkaware 2018]. This may be related to the fact that Drinkaware is funded by the alcohol industry, which has led to much criticism of Public Health England's partnership with the charity [Gilmore, Bauld, and Britton 2018].)

As well as alcohol consumption guidelines, there are other public health strategies to protect the public from the harmful effects of alcohol. After a protracted legal battle against the Scottish Whisky Association, Scotland recently became the first country in the world to introduce a minimum unit price for alcohol (BBC 2018). This was set at 50 pence per unit, which radically altered the pricing of some cheap ciders and spirits in Scotland's supermarkets. Suddenly a half-litre can of strong cider could cost no less than $£ 2$; a half-bottle of whisky could retail for no less than $£ 8$, almost doubling the costs to consumers. The impact of these changes was less apparent in Scotland's pubs, where each unit already cost more, but pubs did have to make adjustments. As stated above, a pint of 4 per cent beer contains just over two units, so the minimum price would be about $£ 1$-well below what most pubs charge anyway. But (empirical research alert!) some pubs seem to have failed to factor in the combined effects of stronger drinks and vouchers. To take one example, a well-known chain was at one point selling "Wobbly Bob" Indian Pale Ale (IPA) at the very reasonable full price of $£ 1.88$. This strong beer is 6.5 per cent alcohol, or 3.7 units, for which the minimum price is $£ 1.85$. No problem, one might think. But a Campaign for Real Ale (CAMRA) voucher (which all members receive) reduces the price by 50 pence-ironic, as that is the minimum price for a unit. This makes a pint of Wobbly Bob £1.38, or 37 pence per unit, meaning that any pub that accepted the voucher would be breaking the law-specifically, the Alcohol (Minimum Pricing) (Scotland) Act 2012. (As well as potentially breaking the law, some pub chains are also breaking the laws of logic. One chain decided to stop selling champagne because of Brexit, while continuing to sell prosecco.)

\section{Rounds and Relative Risk}

It is an accepted part of pub etiquette that each member of a group normally takes it in turn to buy drinks. (Indeed, it is so accepted that great approbation greets the person who is too slow to buy his round, and the efficient buyer rises to get his round when there is still an inch or so left in everyone's glasses, in order to avoid the dreaded limbo of not having a drink, even if only for a couple of minutes.) This social convention has some practical advantages: it is time-saving and fair in that it is turn-based. But it also has several potential drawbacks. It is well known that if someone enjoys several drinks bought by his friends but leaves before buying a round, the resentment that results may not be transient. Furthermore, everyone knows to watch out for the (false) friend who always orders expensive single malt whiskies instead of cheap beer when it's not his round. However, there are more subtle issues too. Often if only a few people have arrived, everyone will be keen to buy the first round because it will be cheaper than a later round when everyone is present. However, the lucky purchaser of round one may find that this saving is outweighed by the disadvantage of having to get back up two or three times to buy the latecomers each a drink when they do finally arrive. There is also the dawning fear that gradually grips the early buyer when it slowly becomes apparent that the evening is going well and there will be therefore need to be $\mathrm{N}+1$ rounds when there are only $\mathrm{N}$ people present, necessitating that he buy two rounds. Overall, the risks involved in being the first buyer probably outweigh those involved in getting a later round.

It should be noted that the fairness of buying rounds is also affected by the relative prices of different types of beer and by people switching to spirits instead, which can be more expensive financially but less so in terms of hangovers and health, given that the typical spirit-based drink (except cocktails) contains only one unit versus more than two units for a pint. If someone drinks spirits or half pints all evening this could create both a drunkenness disparity and unfairness in terms of rounds; the person drinking half pints will only get half as drunk but will end up contributing more than their share in terms of money. It should go without saying that one does not order food as part of a round - unless it is one's own round.

There is also an interesting interrelation between buying rounds and the amount of alcohol consumed by each person during a given evening which is partly 
fuelled by the expectation that everyone will buy a round. Depending on age and capacity, there will come a point at which it is unwise to maintain this rule. Clearly, if there are fifteen people out drinking and everyone buys a round some people will become very unwell. Equally, if there are only three friends having a drink and each buys one round, everyone should feel okay, even if more than two pints of beer technically constitutes a binge according to current guidelines (see previous section). For extremely large groups, subgroups often form in order to make round-buying more manageable and healthy or a kitty is used (see below). But there is a large grey area in between, and the rounds rule often means that the amount of alcohol consumed depends directly on how many people come out. For example, if five friends go out together, one round each or five drinks does not seem ridiculous $(\mathrm{N}=5, \mathrm{R}=1)$. If there are six or seven people present, though, it becomes more dangerous. And small numbers are not necessarily safer; if three friends decide to have one more round after they have each had three drinks, the rounds rule will pressure them to have three more rounds instead on grounds of fairness. There will be some cases where the number of friends present actually reduces rather than increases the number of drinks that each one has; for instance, if there are three people then two rounds each might seem okay but if there are four it is less likely that any more drinks will be bought after the first round of rounds.

In fact, the number of drinks that each person consumes is often determined directly by the number of people in attendance. This is unhealthy, as it means that economic justice (everyone contributes roughly equally) is trumping drinking healthily. Although much public health risk communication about alcohol is not justified by the scientific evidence, we still should not let our alcohol consumption be decided randomly by the number of friends that turns up. Thus, it may be helpful to develop a formula that makes it easier to drink responsibly, while also allowing people to set their own limits - preferably before the first drink, as one of the inhibitions reduced by alcohol is the inhibition to drink more than is sensible.

Let's call $\mathrm{N}$ the number of people present, $\mathrm{R}$ the number of rounds that each person is going to buy, and $\mathrm{D}$ the maximum number of drinks each person wants to have. We then have: $\mathrm{R}=\mathrm{D} / \mathrm{N}$, as the total number of drinks bought should be divided equally between the members of the group. But how should we establish the value of $\mathrm{D}$ ? As stated in the previous paragraph, it is often established by $\mathrm{D}=\mathrm{N}$, or $2 \mathrm{~N}$ or $3 \mathrm{~N}$ in the interests of fairness - everyone gets a round (or multiples of rounds), even if it kills them. If that's the case then the number of rounds each person gets if it's a group of ten is one. But, although it is an awkward subject to broach, pub goers should be more prudent. $\mathrm{D}$ should be established independently in terms of the maximum amount that each person wants to drink in an evening; once one person reaches their own limit, rounds should cease (which could be awkward-as could explaining this formula to your friends in the first place). Box 1 illustrates this formula in action. This is just a rough guide, and all the examples are based on $\mathrm{N}$ being a maximum of four (which would still be a binge if everyone is drinking pints of beer).

Occasionally (very occasionally among some groups of friends) one of the party will decide not to drink any alcohol because he is not well or has work the next day, is driving or is a teetotaller. Normally only the last two of these are regarded as any sort of legitimate defence against incessant urging from one's friends to "go on, have a drink," and even in the case of drivers, friends will offer to pay for a taxi if alcohol is consumed. Another issue raised by not partaking with one's friends is that with each successive drink the relative perceived hilarity of and interest in the conversation will increase in direct proportion to its decreasing actual hilarity and interest but decrease in direct proportion to its actual hilarity and interest for any non-drinkers. This rapidly augmenting disparity may force the non-drinker to go to the bar after all or just to go home. It might be thought that it goes without saying that anyone drinking should not drive home, as doing so puts lives at risk. However, in many countries one drink is still legally if perhaps not

Box 1 A rough guide to calculating a healthy number of rounds

4 drinks $/ 8$ people, $r=0.5$, which means splitting into two groups of four and getting one round each for that group.

4 drinks $/ 2$ people, $r=2$, two rounds each

4 drinks $/ 3$ people $r=1.3$, one round each and one extra (awkward)

4 drinks $/ 4$ people, $r=1$, one round each

4 drinks $/ 5$ people $r=0.8$, probably end up having five drinks with one round each

4 drinks $/ 6$ people $4=0.6$, just have three drinks each in two groups - otherwise six drinks

4 drinks $/ 7$ people $r=0.57$, this is very awkward and hopefully someone will not turn up 
socially permissible. A recent study found that drinking even "only" up to the maximum permitted in England and Wales increases the risk of involvement in a crash 14-fold - a risk worth considering (Romano et al. 2014).

The alternative to buying rounds is to have a kitty, which is often the solution used for very large groups of drinkers. While it avoids many of the complications of rounds, the kitty is more open to exploitation because it is one pot that anyone can dip into; the nature of the larger group and lack of regularity conferred by rounds also increases the risk of embezzlement. However, sometimes the kitty is treated as a shared resource and everyone takes it in turns to go up; this is more equitable than the model where one person is responsible for the kitty and is the only one who has to go to the bar.

\section{Conclusion: Last Orders and the Post-Pub Conversation}

The first part of the post-pub conversation actually takes place in the pub; it concerns whether to go anywhere else after leaving it. Generally the likelihood of going to a nightclub (i.e. disco, not strip joint) will depend largely on whether everyone got one round each or slightly more - two rounds and up and you're doomed, and so is tomorrow. The likelihood of going somewhere else and carrying on drinking is also linked to whether the shout of "last orders gentlemen please" coincides with the buying of the last planned round. If it does, hopefully everyone will go home. If it does not, then going on to a club might be necessary for the sake of equity, with all the potential health hazards that entails.

In the end, going to the pub is largely about dialogue, and alcohol certainly enables that. But if you drink too much, you might find that all you know the morning after is that you know nothing about the night before. I hope to have illustrated in this article how even something as seemingly simple as going to the pub can raise interesting philosophical and ethical issues. Arranging a night in the pub can actually be quite fraught; health warnings need to be taken with a pinch of salt; and despite that, if we actually thought more about what we're doing in terms of drinking, we could lead happier and healthier lives.

\section{Compliance with Ethical Standards}

Conflict of Interest Declaration I like going to the pub but none of this article was written there. I was not drunk while writing any of this article but may have been mildly hungover when I had the idea for it.

Publisher's Note Springer Nature remains neutral with regard to jurisdictional claims in published maps and institutional affiliations.

\section{References}

BBC News. 2018. Scotland ends cheap booze as minimum price starts. May, 1. https://www.bbc.co.uk/news/uk-scotland43948081. Accessed December 19, 2018.

Drinkaware. 2018. Binge drinking. https://www.drinkaware.co. uk/alcohol-facts/drinking-habits-and-behaviours/bingedrinking/. Accessed December 19, 2018.

Gilmore I., L. Bauld, and J. Britton. 2018. Public Health England's capture by the alcohol industry. BMJ 362: k3928.

Romano, E., P. Torres-Saavedra, R.B. Voas, and J.H. Lacey. 2014. Drugs and alcohol: Their relative crash risk. Journal of Studies on Alcohol and Drugs 75(1): 56-64.

Shaw, D. 2016. Drunk on risk: How the Chief Medical Officers' alcohol guidelines are demonizing drink. BMJ 352: 1704 .

Spiegelhalter, D. The risks of alcohol (again). Winton Centre for Risk and Evidence Communication, August 23. https://medium.com/wintoncentre/the-risks-of-alcoholagain-2ae8cb006a4a. Accessed December 19, 2018.

The Lancet. 2018. The Lancet: Alcohol is associated with 2.8 million deaths each year worldwide [press release]. EurekAlert! August 23. https://www.eurekalert.org/pub_releases/2018-08/tltla082218.php. Accessed January 08, 2019.

UK National Health Service. 2016. Alcohol support. https://www. nhs.uk/live-well/alcohol-support/binge-drinking-effects/. Accessed December 19, 2018.

UK Department of Health. 2016. UK Chief Medical Officers' Alcohol Guidelines Review Summary of the proposed new guidelines. https://assets.publishing. service.gov. uk/government/uploads/system/uploads/attachment data/file/489795/summary.pdf. Accessed December 19, 2018.

Weaver, M. 2016. New tough alcohol guidelines not scaremongering, says chief medical officer. The Guardian, January 8. https://www.theguardian.com/society/2016/jan/08/toughdrinking-guidelines-not-scaremongering-says-chief-medicalofficer. Accessed January 8, 2019. 